$\begin{array}{ccc}\text { Tersedia online di: http:/lejournal-balitbang.kkp.go.id/index.phpljppi } & \text { JURNAL } \\ \text { e-mail:jppi.puslitbangkan@gmail.com } & \text { PENELITIN } \\ \text { PERIKANAN } & \text { INDONESIA } \\ \text { JURNAL PENELITIANPERIKANANINDONESIA } & \text { Volume 24 Nomor 3 September 2018 } \\ \text { p-ISSN: 0853-5884 } & \text { e-ISSN: 2502-6542 } \\ \text { Nomor Akreditasi RISTEKDIKTI: 21/E/KPT/2018 }\end{array}$

\title{
KARAKTERISTIK POPULASI DAN TINGKAT PEMANFAATAN KEPITING BAKAU (Scylla serrata Forskal 1775) DI PERAIRAN ASAHAN DAN SEKITARNYA, SUMATERA UTARA
}

\section{POPULATION CHARACTERISTICS AND EXPLOITATION LEVEL OF GIANT MUD CRAB (Scylla serrata Forskal, 1775) IN ASAHAN AND ITS ADJACENT WATERS, NORTH SUMATERA}

\author{
Andina Ramadhani Putri Pane ${ }^{* 1}$ dan Ali Suman ${ }^{1}$ \\ ${ }^{1}$ Balai Riset Perikanan Laut, Cibinong Komplek Raiser Ikan Hias Jl. Raya Bogor KM 47 Cibinong-Bogor, Indonesia \\ Teregistrasi I tanggal: 04 September 2017; Diterima setelah perbaikan tanggal: 08 Mei 2018; \\ Disetujui terbit tanggal: 18 Juli 2018
}

\begin{abstract}
ABSTRAK
Peningkatan jumlah ekspor kepiting (Scylla serrata Forskal, 1775) di wilayah perairan Asahan memacu peningkatan penangkapan yang dapat berpengaruh terhadap populasi dan kelestarian. Penelitian ini bertujuan untuk mengetahui karakteristik populasi dan tingkat pemanfaatan kepiting bakau di perairan Asahan dan sekitarnya. Pengambilan sampel dilakukan setiap bulan dari Januari sampai dengan Nopember 2016 di tempat pendaratan kepiting oleh enumerator. Data dianalisa dengan metode Electronic LEngth Frequency Analisys-I (ELEFAN-I) dari FAO-ICLARM Stock Assessment Tools II (FiSAT II). Hasil penelitian menunjukkan pola pertumbuhan kepiting bakau bersifat allometrik negatif pada kisaran lebar karapas antara 85 - $175 \mathrm{~mm}$ dan bobot tubuh 127 $1.152,5$ gram. Rata-rata ukuran lebar karapas tertangkap dengan jaring dan bubu adalah 118,6 $\mathrm{mm}$ dan ukuran matang gonad pertama kali adalah 120,6 mm. Laju pertumbuhan (K) 1,38 per tahun dan lebar karapas maksimum $\left(\mathrm{CW}_{\infty}\right)$ sebesar $201 \mathrm{~mm}$. Laju kematian total $(Z)$ sebesar 3,59 per tahun, laju kematian karena penangkapan $(F)$ dan laju kematian alami $(\mathrm{M})$ masingmasing 2,27 per tahun dan 1,32 per tahun. Laju pemanfaatan (E) kepiting bakau di perairan Asahan adalah 0,63 per tahun atau sudah melebihi nilai optimum penangkapan. Agar sumber daya kepiting terjamin kelestariannya, maka harus dilakukan pengurangan upaya penangkapan sekitar $26 \%$.
\end{abstract}

Kata Kunci: Karakteristik; Populasi; tingkat pemanfaatan; Scylla serrate; Asahan; Sumatera Utara

\begin{abstract}
Increase in the volume of giant mud crab exports (Scylla serrata Forskal, 1775) in the Asahan waters stimulate the increasing catches that affect population and sustainability. This study aims to determine the population characteristics and the exploitation level of giant mud crab in Asahan and adjacent waters. Monthly sampling was done from January to November 2016 at crab landing sites by enumerator. The data were analyzed using Electronic Length Frequency Analysys-I (ELEFAN-I) method available in FAO-ICLARM Stock Assessment Tools II (FiSAT II) program. The results showed that the growth pattern of giant mud crab was negative allometric with carapace width between 85 - $175 \mathrm{~mm}$ and individual body weight 127 - 1,152.5 grams. The average carapace's width caught by net and trap was $118.6 \mathrm{~mm}$ and the size of gonad first maturity was $120.6 \mathrm{~mm}$. Growth rate $(K) 1.38$ per year and maximum carapace width $(C W \infty)$ of $201 \mathrm{~mm}$. Total mortality rate $(Z)$ of 3.59 per year, mortality rate due to fishing $(F)$ and natural mortality rate $(M)$ was 2.27 per year and 1.32 per year respectively. The rate of exploitation (E) of mangrove crab in Asahan waters was 0.63 or has exceeded the optimum value. For the sustainability of crab resource a reduction of $26 \%$ in fishing effort is suggested.
\end{abstract}

Keywords: Characteristics; Population; Explotation Level; Scylla serrate; Asahan; North Sumatera 


\section{PENDAHULUAN}

Kepiting bakau (Scylla spp.) merupakan salah satu komoditas perikanan penting yang memiliki nilai ekonomis tinggi di Asia Tenggara (Le Vay, 1998; Cristensen et al., 2004). Komoditas ini juga sangat potensial untuk terus dikembangkan dalam bidang akuakultur (Kathirvel et al., 2004; Ruscoe et al., 2004; Mohanty et al., 2006) untuk mendukung KEPMEN KP Nomor 50 Tahun 2017 bahwa estimasi potensi kepiting di seluruh WPP RI yaitu 43.446 juta ton. Kepiting bakau memiliki popularitas yang terus meningkat karena kualitas dagingnya lezat dan bergizi (Marichamy \& Rajapackian, 2001).

Kepiting bakau telah dimanfaatkan sejak tahun 1980 sebagai komoditas penting dan memiliki nilai ekonomis. Menurut Cholik (1999) untuk memenuhi permintaan pasar, produksi kepiting bakau masih bergantung pada penangkapan dari alam. Kepiting bakau yang dimanfaatkan di Indonesia terdiri dari empat jenis, yaitu : Scylla serrata, S. tranquebarica, S. olivacea dan S. paramamosain dimana sekitar 80 $\%$ didominasi jenis S.serrata (Keenan et al., 1998). Menurut La Sara (2010) bahwa Scylla sp. tersebar di Indonesia terutama baik di wilayah pesisir yang mempunyai mangrove maupun daerah estuari mulai dari Sumatera sampai dengan Papua.

Kepiting bakau ( $S$. serrata) masih menjadi target pemanfaatan oleh nelayan di perairan Asahan dan sekitarnya karena nilai ekonomi. Pada saat ini, penangkapan sudah intensif menggunakan jaring dan bubu kepiting. Jenis kepiting bakau yang ditemukan di perairan Asahan hanya ada 2 (dua) jenis yaitu $S$. serrata dan S. olivacea, namun jenis $S$. serrata lebih dominan. Permintaan kepiting bakau untuk pasar domestik maupun ekspor semakin meningkat dari tahun ke tahun dan kondisi ini menyebabkan meningkatnya intensitas penangkapan. Berdasarkan data Stasiun Karantina Ikan Kementerian Kelautan dan Perikanan Asahan - Tanjungbalai lalu lintas kepiting meningkat dari tahun 2014 sebesar 64.732 ekor menjadi 163.143 ekor tahun 2016. Data tangkapan kepiting hanya diperoleh dari Stasiun Karantina Ikan KKP sesuai dengan Permen KKP Nomor 1 Tahun 2015 dan Nomor 56 Tahun 2016 yang mengatur ukuan kepiting yang boleh ditangkap dan diekspor. Karena kepiting yang diluar ketentuan dan diperjualbelikan secara lokal tidak tercatat pada stasiun tersebut.

Populasi kepiting bakau akan terancam karena tingginya eskploitasi dan dalam jangka panjang dapat menimbulkan kepunahan sumberdaya kepiting bakau. Untuk mempertahankan sumber daya kepiting bakau agar terjamin kelestariannya maka harus dikelola secara berkelanjutan. Kebijakan pengelolaan tersebut memerlukan data populasi dan tingkat pemanfaatan.

Parameter pertumbuhan dapat menjadi salah satu dasar untuk menghitung populasi dan tingkat pemanfaatan sumberdaya ikan (Effendi, 2002). Sampai saat ini belum ada informasi karateristik populasi dan tingkat pemanfaatan kepiting bakau di perairan Asahan dan sekitarnya. Dalam kaitan tersebut maka tulisan ini akan membahas parameter pertumbuhan dan aspek lainnya yang menjadi dasar dalam perhitungan populasi dan tingkat pemanfaatan kepiting bakau di perairan tersebut. Hasil penelitian diharapkan dapat digunakan sebagai dasar untuk pengelolaan sumber daya kepiting bakau di perairan Asahan dan sekitarnya secara berkelanjutan.

\section{BAHAN DAN METODE Pegumpulan Data}

Penelitian dilakukan di perairan Asahan dan sekitarnya di tempat pengumpul kepiting pada Januari sampai dengan Nopember 2016 dengan metode pengamatan langsung di tempat pendaratan kepiting dan pengumpulan data biologi bulanan dibantu oleh 1 (satu) orang tenaga enumerator. Selama penelitian diamati 1.940 ekor sampel kepiting jantan dan betina. Lokasi pengambilan sampel di 4 (empat) pendaratan kepiting dan daerah penangkapan kepiting bakau disertakan pada Gambar 1. Semua sampel ditimbang dengan menggunakan timbangan digital dengan ketelitian 0,1 gram dan diukur dengan jangka sorong (kaliper) dengan ketelitian 0,01 mm. Parameter biologi yang dicatat adalah ukuran lebar karapas, bobot individu, jenis kelamin dan tingkat kematangan gonad kepiting betina. 


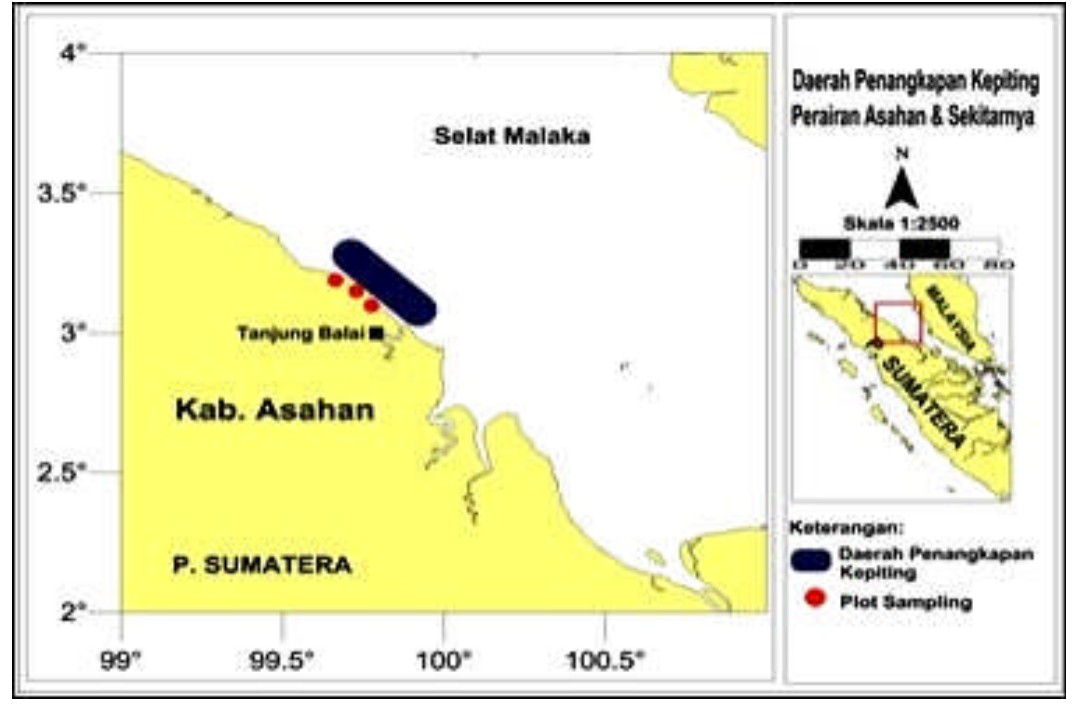

Gambar 1. Lokasi sampling dan daerah penangkapan kepiting bakau di perairan Asahan dan sekitarnya.

Figure 1. Sampling site and fishing ground of giant mud crab in Asahan and adjacent waters.

\section{Analisisi Data}

Hubungan lebar karapas dan bobot tubuh dianalisis dengan persamaan Ball \& Rao (1984):

$\mathrm{W}=\mathrm{a} C \mathrm{~W}^{\mathrm{b}}$ kali matang gonad $\left(\mathrm{P}_{\mathrm{cmm}}\right)$ dan kelas lebar karapas dengan persamaan sebagai berikut (King, 1995):

$$
P C W m=\frac{1}{1+\exp (a C W+b)}
$$

dimana:

$\mathrm{P}_{\text {cwm }}=$ Ukuran pertama kali matang gonad

$\mathrm{Cl}^{\mathrm{Cwm}}=$ lebarkarapas $(\mathrm{mm})$

a $=$ intercept

$\mathrm{b}=$ slope

Parameter pertumbuhan ( $\mathrm{K}$ dan $\mathrm{CW} \infty$ ) dirunut dengan metode Electronic LEngth Frequency Analisys-I (ELEFAN-I) yang dikemas dalam program FAO-ICLARM Stock Assessment Tools II (FiSAT II) yang mengacu kepada Gayanilo et al., 1993. Laju kematian total ( $Z$ ) diduga melalui kurva hasil tangkapan yang dilinierkan (linierized catch curve) dengan interval waktu yang sama. Nilai Z merupakan kemiringan (slope) dari kurva regresi antara Ln N/t dengan umur relatif sesuai dengan rumus sebagai berikut (Sparre \& Venema, 1999):

$$
\operatorname{Ln} \mathrm{N} / \mathrm{t}=\mathrm{a}-\mathrm{Zt}
$$

frekuensi kumulatif ukuran kepiting yang tertangkap. Dibuat grafik hubungan antara distribusi kelas lebar karapas (sumbu $\mathrm{x}$ ) dengan persentase kumulatif jumlah kepiting (sumbu y), sehingga terbentuk kurva berbentuk $\mathrm{S}$ (sigmoid). Nilai $\mathrm{CW}_{\mathrm{c}}$ dinyatakan sebagai titik potong antara kurva $50 \%$ frekuensi kumulatif dengan nilai lebar karapas (Saputra, 2009).

Ukuran pertama kali matang gonad (length at first maturity, $\mathrm{CW}_{\mathrm{m}}$ ) kepiting betina diperoleh berdasarkan fungsi logistik dengan memasukkan rata-rata pertama dimana:

$\mathrm{N}=$ banyaknya kepiting pada waktu $\mathrm{t}$

$\mathrm{t}=$ waktu yang diperlukan untuk tumbuh suatu kelas panjang

$\mathrm{a}=$ hasil tangkapan yang dikonversikan terhadap panjang

Parameter pertumbuhan lainnya, yaitu umur teoritis pada saat lebar kepiting sama dengan nol $\left(=t_{0}\right)$ 
dihitung melalui rumus empiris Pauly (1980) dalam Sparre \& Venema (1999) sebagai berikut:

$\log \left(-t_{0}\right)=-0,3922-0,2752 \log \left(C_{\infty}\right)-1,308 \log (K) \ldots(4)$

dimana:

$\mathrm{CW}_{\infty}=$ lebar asimptot kepiting bakau $(\mathrm{mm})$

$\mathrm{K}=$ koefisien pertumbuhan (per tahun)

$\mathrm{t}_{\mathrm{o}}=$ umur teoritis pada saat lebar karapas sama dengan nol (tahun)

Pendugaan kematian alamiah (M) dilakukan dengan menggunakan rumus empiris Pauly (1980) sebagai berikut :

$\log (M)=-0,0066-0,279 \log \left(C W_{\infty}\right)+0,6543 \log$

dimana:

$$
(\mathrm{K})+0,4634 \log (\mathrm{T}) \text {........ }
$$

$\mathrm{M}=$ laju kematian alamiah

$\mathrm{L}=$ lebar karapas maksimun $(\mathrm{mm})$

$\mathrm{K}=$ laju pertumbuhan ( $\mathrm{mm} /$ tahun)

$\mathrm{T}=\operatorname{suhu}\left({ }^{\circ} \mathrm{C}\right)$

Nilai laju kematian karena penangkapan (F) diperoleh dari pengurangan antara laju kematian total (Z) dengan laju kematian alamiah (M). Laju pengusahaan dihitung sebagai $E=F / Z$ (Sparre \& Venema, 1999).

\section{HASIL DAN BAHASAN \\ Hasil}

\section{Hubungan Lebar Karapas dengan Bobot Tubuh dan Nisbah Kelamin}

Hubungan antara lebar karapas dan bobot tubuh dengan nilai konstanta $a=0.0126$ dan $b=2,1284$, sehingga persamaan hubungan antara lebar karapas dengan berat tubuh adalah $\mathrm{W}=0.0126 \mathrm{CW}^{2.1284}$ (Gambar 2). Nilai ini menunjukkan hubungan pertumbuhan allometrik negatif yang artinya pertambahan lebar tubuh lebih lambat dari pertambahan bobot tubuh kepiting bakau.

Nisbah kelamin kepiting bakau betina dengan jantan di perairan Asahan dan sekitarnya adalah 1,0 : 7,1 dan berdasarkan uji Chi-kuadrat maka diketahui bahwa nisbah kelamin tidak seimbang. Sebaran tingkat kematangan gonad kepiting bakau yang belum matang (immature) mulai dari 100 - $140 \mathrm{~mm}$ dan yang matang gonad (mature) mulai dari $110-160 \mathrm{~mm}$ yang dominan pada ukuran $125 \mathrm{~mm}$ (Gambar 3).

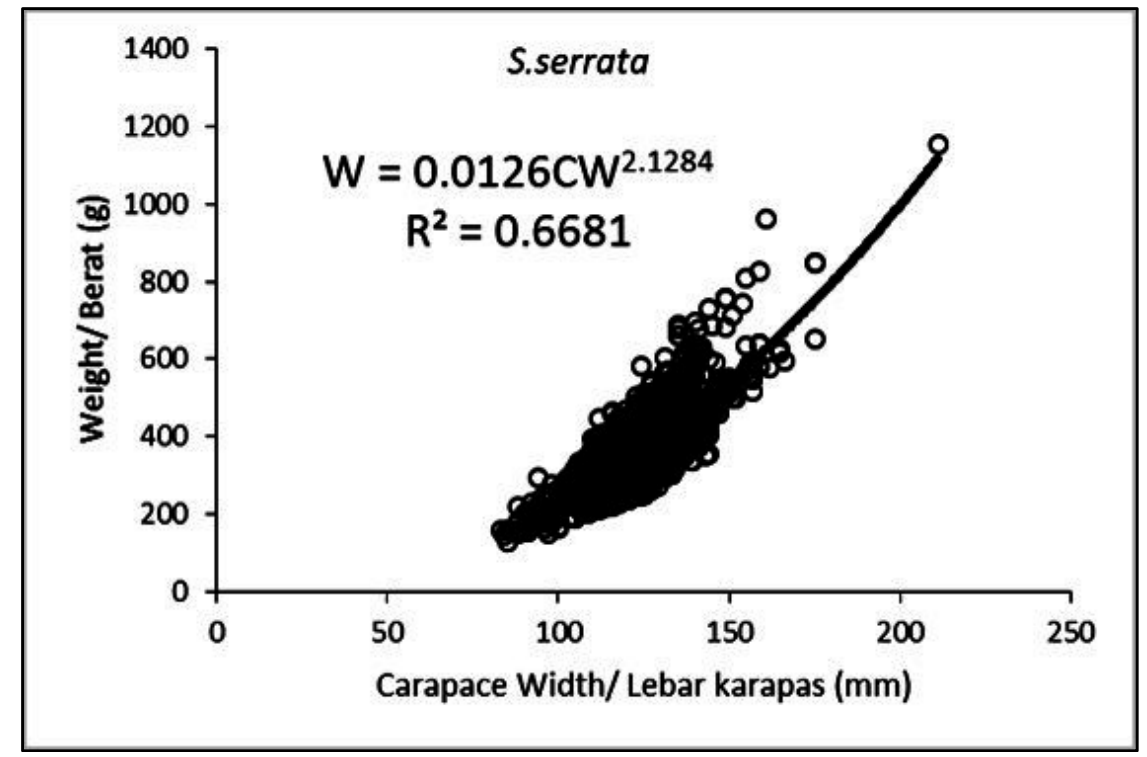

Gambar 2. Hubungan lebar karapas dengan bobot tubuh kepiting bakau. Figure 2. Carapace Width-weight relationship of giant mud crabs. 


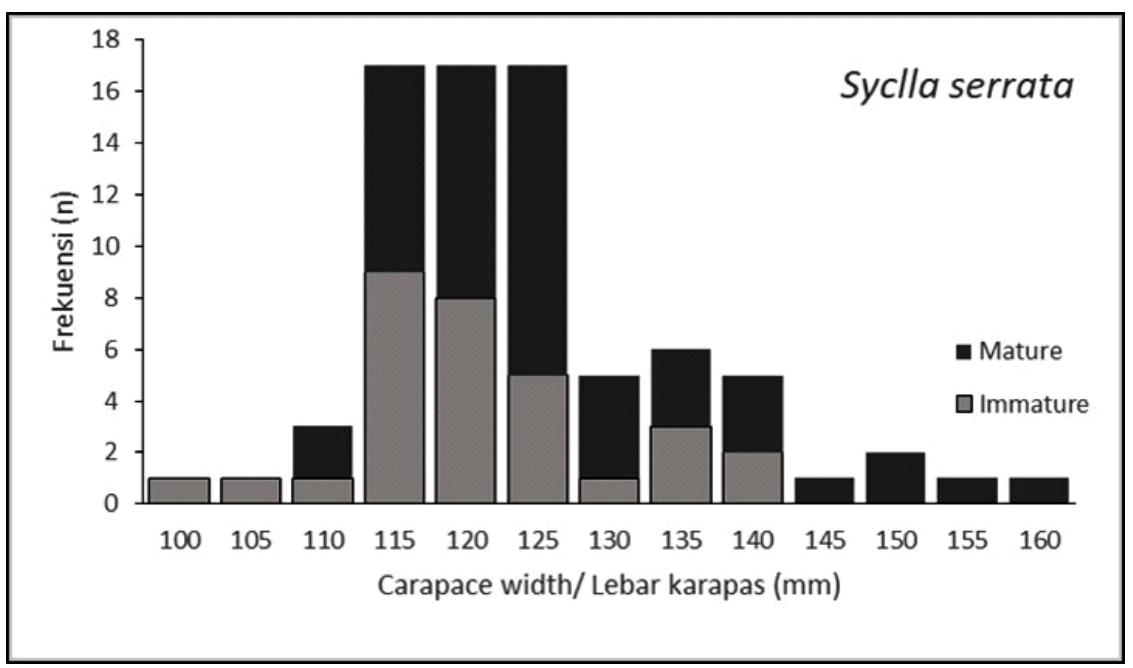

Gambar 3. Sebaran tingkat kematangan gonad berdasarkan ukuran kepiting bakau.

Figure 3. Distribution Gonad Maturity based on site of giant mud crab.

Kepiting bakau yang ditemukan selama penelitian berada pada kisaran ukuran lebar karapas kepiting jantan antara 85 - $175 \mathrm{~mm}$ dengan rata-rata 115 $130 \mathrm{~mm}$, untuk kelamin betina mempunyai kisaran antara 85-150 mm dengan rata-rata pada 120 - 130 $\mathrm{mm}$. Sebaran ukuran kepiting $105-140 \mathrm{~mm}$, kepiting jantan dominan tertangkap 3-11 kali daripada kepiting betina. Pada selang ukuran $85-100 \mathrm{~mm}$ dominan ditemukan betina dan pada selang ukuran 100 - 140 $\mathrm{mm}$ kepiting jantan dan betina mempunyai pola sebaran ukuran yang sama. Namun secara umum kepiting jantan mempunyai lebar karapas yang lebih dari yang betina (Gambar 4).

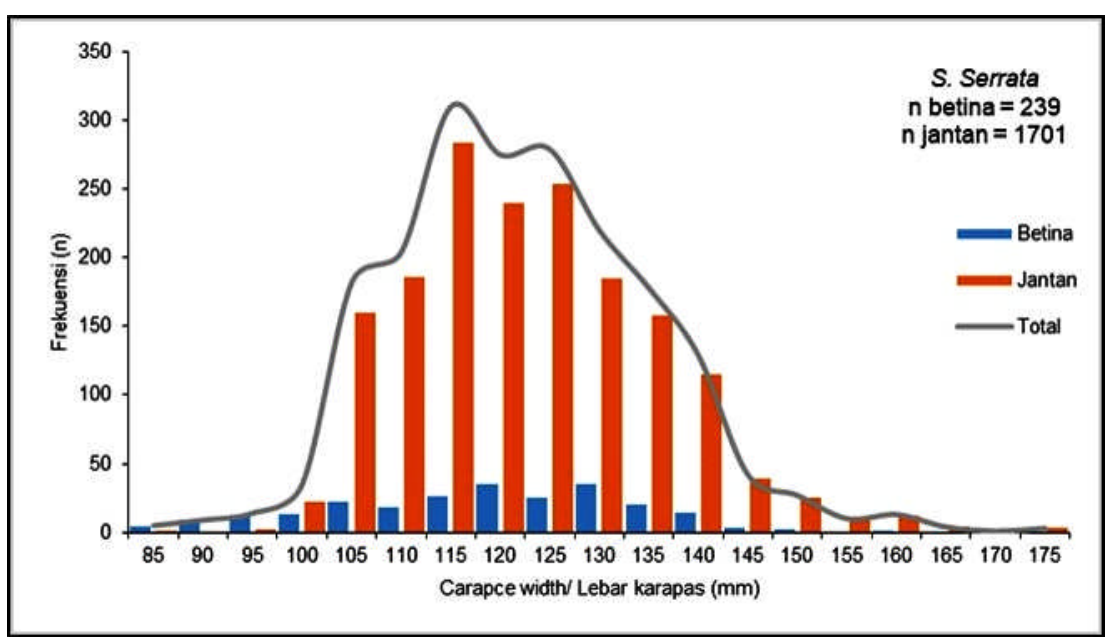

Gambar 4. Struktur ukuran kepiting bakau (S. serrata) di perairan Asahan dan sekitarnya berdasarkan jenis kelamin, Januari - Nopember 2016.

Figure 4. Size structure of giant mud crabs (S. serrata) in Asahan and its adjacent waters by sex, Januari - November 2016.

Parameter Pertumbuhan, Ukuran Pertama Kali Tertangkap (CW), Ukuran Pertama Kali Matang Gonad $\left(\mathrm{CW}_{m}\right)$ dan Tingkat Pemanfaatan

Hasil analisis berdasarkan data yang diperoleh di lapangan disajikan pada Tabel 1. Nilai laju pertumbuhan (K) dan lebar karapas maksimum $(\mathrm{CW} \infty)$ pertumbuhan kepiting bakau di perairan Asahan dan sekitarnya mengikuti persamaan $\mathbf{L t}=\mathbf{2 0 1}\left[1-\mathrm{e}^{-1,38(\mathrm{t}}-\right.$
${ }^{0.06}$ ]. Tingkat pemanfaatan (E) kepiting bakau sebesar 0,63 per tahun yang menggambarkan pemanfaatan kepiting bakau di perairan Asahan sudah lebih tangkap (overfishing).

Nilai ukuran pertama kali tertangkap $\left(\mathrm{CW}_{\mathrm{c}}\right)$ kepiting bakau di perairan Asahan dan sekitarya adalah $118.6 \mathrm{~mm}$ dan nilai pertama kali matang go$\operatorname{nad}\left(\mathrm{CW}_{\mathrm{m}}\right)$-nya sebagai 120,6 $\mathrm{mm}$ (gambar 5). 
Tabel 1. Beberapa nilai parameter populasi kepiting bakau di perairan Asahan dan sekitarnya pada tahun 2016

Tabel 1. Population parameters of giant mud crabs caught in Asahan its adjacent waters in 2016

\begin{tabular}{lcc}
\hline Parameter & Satuan & Nilai \\
\hline Ukuran pertama kali tertangkap $\left(\mathrm{CW}_{\mathrm{c}}\right)$ & $\mathrm{mm}$ & 118.6 \\
Ukuran pertama kali matang gonad $\left(\mathrm{CW}_{\mathrm{m}}\right)$ & $\mathrm{mm}$ & 120.6 \\
Lebar karapas maksimum $\left(\mathrm{CW}_{\infty}\right)$ & tahun & 201 \\
Laju pertumbuhan $(\mathrm{K})$ & tahun & 1,38 \\
Umur pada saat lebar sama dengan nol $\left(\mathrm{t}^{0}\right)$ & tahun & $-0,06$ \\
Kematian total $(\mathrm{Z})$ & tahun & 3,59 \\
Kematian alamiah $(\mathrm{M})$ & tahun & 1,32 \\
Kematian penangkapan $(\mathrm{F})$ & tahun & 2,27 \\
Tingkat pemanfaatan $(\mathrm{E})$ & tahun & 0,63 \\
\hline
\end{tabular}

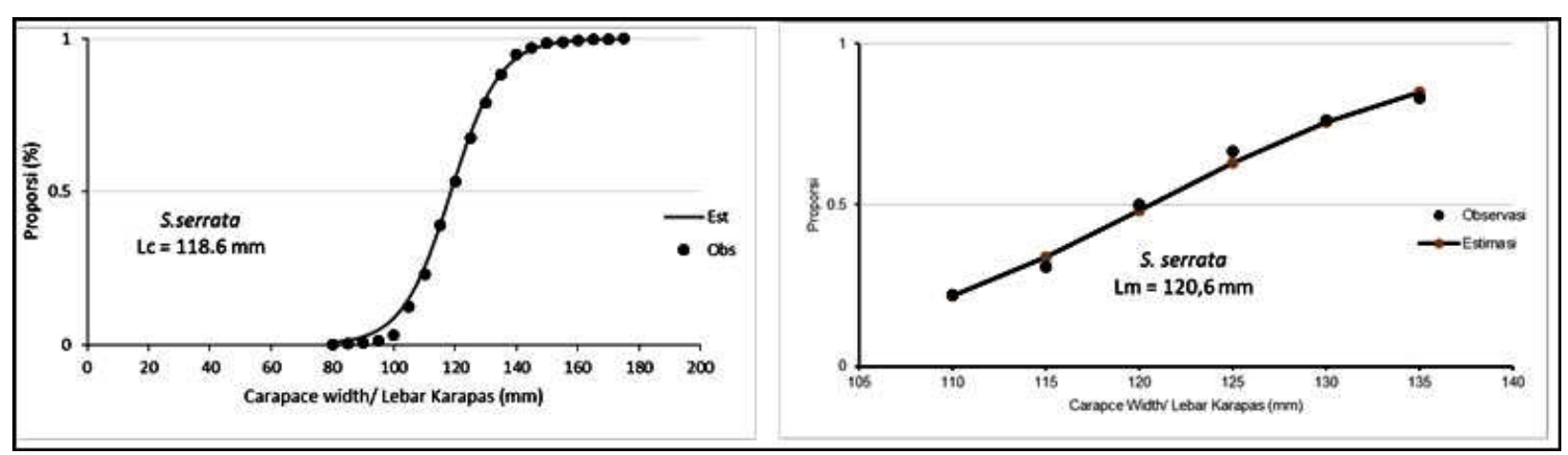

Gambar 5. Nilai $\mathrm{CW}_{\mathrm{c}}$ dan $\mathrm{CW}_{\mathrm{m}}$ kepiting bakau (S. serrata) di perairan Asahan dan sekitarnya.

Figure 5. $\quad C W_{c}$ and $C W_{m}$ of giant mud crabs (S. serrata) in Asahan and its adjacent waters.

\section{Bahasan}

Pola pertumbuhan kepiting bakau yang bersifat allometrik negatif menunjukan bahwa pertumbuhan lebar tubuh lebih lambat dibanding pertumbuhan bobotnya dan sejalan dengan penelitian Asmara et al. (2011) di Cilacap namun berbeda dengan Alamsyah \& Megawati (2017) di Sinjai Timur dan Yusrudin (2016) di Sukolilo. Adanya perbedaan tersebut karena model pertumbuhan individual bergantung pada ketersediaan makanan dan suhu perairan, jenis kelamin, umur dan penyakit (Effendie, 2002; Monterio, 2002 dalam Fauzi et al., 2013).

Jumlah kepiting jantan lebih banyak daripada betina, rasio kelamin yang tidak seimbang berkaitan dengan proses penambahan baru yang dapat terhambat akibat menurunnya populasi kepiting bakau betina. Fenomena yang sama didapatkan juga di perairan Mayangan, Subang (Syam et al, 2011) dan hal ini yang berbeda didapatkan di Muara Sungai Cenrara, Sulawesi Selatan (Gunarto et al., 1999). Penyebab perbedaan rasio kelamin tersebut dapat terjadi karena dipengaruhi tekanan penangkapan dan faktor migrasi (Suman, 2004; Edrus \& Syam, 2004). Menurut Hill (1975) bahwa penyebab dominasi kepiting jantan karena habitat hidupnya hanya di perairan hutan bakau atau muara sungai sementara kepiting betina mengalami pola migrasi setelah melangsungkan perkawinan di perairan mangrove dan secara berangsur-angsur beruaya ke laut.

Lebar karapas pada saat kepiting matang gonad berkisar antara 110 - $160 \mathrm{~mm}$ dengan dominan pada ukuran $125 \mathrm{~mm}$, tidak dapat dijadikan dasar bahwa kepiting bakau sedang dalam pemijahan, karena kematangan gonad dipengaruhi kualitas perairan. Luasan hutan mangrove di Kabupaten Asahan tahun 2006 sebanyak 18.785 Ha dan Kabupaten Deli Serdang $21.051 \mathrm{Ha}$ (Onrizal, 2010) yang merupakan lokasi utama penangkapan kepiting oleh nelayan. Lokasi tersebut dinyatakan sebagai habitat yang cocok untuk kepiting, sesuai dengan pernyataan Tahmid et al (2015) bahwa kualitas habitat mempunyai korelasi positif terhadap pertumbuhan karapas dan bobot kepiting bakau dan memberikan pengaruh pada kelimpahan kepiting dan fluktasi hasil tangkapan.

Sebaran ukuran lebar karapas kepiting betina dan jantan memiliki pola yg sama yaitu pada ukuran 100 - $140 \mathrm{~mm}$ mempunyai selang ukuran $105-140 \mathrm{~mm}$. Kepiting di perairan ini lebih besar dibandingkan yang 
ditemukan diperairan Mayang, Subang berukuran 55$80 \mathrm{~mm}$ (Syam et al, 2011), di perairan Cilacap 32,5$122,5 \mathrm{~mm}$ (Asmara et al, 2011).

Menurut Sparre \& Venema (1999), semakin rendah koefisien pertumbuhan (K), semakin lama waktu yang dibutuhkan spesies tersebut untuk mendekati panjang asimtotik. Sebaliknya, semakin tinggi koefisien pertumbuhan, maka semakin cepat waktu yang dibutuhkan spesies tersebut mendekati panjang asimtotik. Nilai laju pertumbuhan (K) kepiting bakau di perairan Asahan adalah 1,38 per tahun dan hal ini menunjukkan bahwa laju pertumbuhannya tergolong cepat mencapai panjang asimtotiknya. Semakin cepat pertumbuhan maka akan semakin cepat mencapai ukuran dewasa dan semakin cepat untuk masuk ke dalam tahap pemijahan. Fenomena ini berbeda apabila dibandingkan hasil penelitian di berbagai perairan lainnya di Indonesia (Tabel 2).

Tabel 2. Laju pertumbuhan $(\mathrm{K})$ dan lebar karapas maksimum $(\mathrm{CW} \infty)$ kepiting bakau (S. serrata) pada berbagai perairan di Indonesia

Table 2. The growth rate $(K)$ and maximum carapace width $(C W \infty)$ of giant mud crabs (S. serrata) in some waters area in Indonesia

\begin{tabular}{ccc}
\hline Perairan (Waters) & K (per tahun) CWoo $(\mathbf{m m})$ & Sumber (Source) \\
\hline Asahan & $1,38201,0$ & Penelitian ini (2016) \\
Kotabaru & $1,33160,0$ & BPPL (2011) \\
Bone & $1,08165,0$ & BPPL (2011) \\
Kutai Timur & $0,45-1,55147-155$ & Wijaya et al (2010) \\
Subang & $0,59147,0$ & Syam et al (2011) \\
Gorontalo & $0,39188,49$ & Monoarfa et al (2013) \\
Surabaya & $1,3280,58$ & Yusrudin (2016) \\
\hline
\end{tabular}

Perbedaan parameter pertumbuhan dapat disebabkan oleh perbedaan lokasi perairan (Widodo \& Suadi, 2006) sebagai faktor eksternal. Selat Malaka memiliki tingkat kesuburan tinggi dan tingkat kandungan klorofil tinggi pada bulan Juli, Agustus dan September (Realino et al., 2006; Syech \& Martin, 2007 ) yang sangat mendukung pertumbuhan kepiting.

Berdasarkan hasil analisa $40 \%$ kepiting di perairan ini mempunyai nilai $\mathrm{CW}_{c}$ lebih kecil daripada nilai $\mathrm{CW}_{m}$ dan hal ini menunjukkan bahwa hampir separuh kepiting yang tertangkap belum sempat melakukan pemijahan. Fenomena ini juga dalam jangka panjang akan mengganggu kelestarian sumber daya kepiting, karena tidak memberi kesempatan pada induk kepiting bakau untuk memijah bagi terjaminnya penambahan baru. Untuk mencegah terjadinya degradasi stok di perairan Asahan ini, maka secepat mungkin harus dilakukan pengaturan ukuran mata jaring dan ukuran lubang/celah bubu kepiting yang digunakan pada penangkapan kepiting bakau ini. Ukuran mata jaring dan ukuran celah bubu harus lebih besar daripada ukuran karapas kepiting pertama kali memijah.

Ukuran rata-rata pertama kali matang gonad $\left(\mathrm{CW}_{\mathrm{m}}\right)$ kepiting bakau di peraian Asahan adalah sebesar $120,6 \mathrm{~mm}$ dan ini lebih kecil di perairan Kotabaru sebesar 146,39 mm (BPPL, 2011). Adanya perbedaan rata-rata ukuran pertama kali matang $\left(\mathrm{CW}_{\mathrm{m}}\right)$ pada berbagai perairan dipengaruhi oleh ketersediaan makanan dan kondisi lingkungan perairan seperti suhu dan salinitas. Simanjuntak (2009) menyatakan bahwa suhu menjadi faktor dalam mengatur proses kehidupan dan penyebaran organisme perairan. Ratarata suhu di perairan Asahan berdasarkan data dari kantor BMKG stasiun Deli Serdang pada tahun 2016 berkisar antara $25,3^{\circ} \mathrm{C}-29,6^{\circ} \mathrm{C}$ (BMKG,2016). Suhu tersebut sesuai dengan pendapat Cholik (2005) bahwa suhu yang baik untuk kehidupan $S$. serrata adalah $18^{\circ} \mathrm{C}-35^{\circ} \mathrm{C}$, namun yang paling ideal adalah $25-$ $30^{\circ} \mathrm{C}$. Syech \& Malik (2013) menyatakan bahwa konsentrasi distribusi reflektan salinitas perairan Selat Malaka antara $0,07 \%-0,45 \%$ yang menunjukkan adanya kehidupan fitoplankton. Karim (2008) juga menyatakan bahwa kepiting bakau (S.olivacea) dapat beradaptasi dengan salinitas basal tertinggi $5 \%$ o dan terendah $25 \%$.

Suhu dan salinitas merupakan unsur penting dalam keseburan perairan karena berhubungan dengan keberadaan fitoplankton sebagai komponen utama rantai makanan bagi biota di perairan. Wiadnyana (2000) menyatakan bahwa perubahan fungsi perairan disebabkan oleh berubahnya kualitas dan kuantitas plankton. Kepiting mempunyai habitat di dasar perairan yang berlumpur karena banyak terdapat bahan makanan. Menurut Suryani (2006), kepiting bakau biasanya berada di daerah berlumpur di hutan mangrove dan membuat lubang-lubang. Siahanenia (2009) menambahkan kepiting bakau mempunyai maxiliped dilengkapi rambut-rambut halus, yang diduga berfungsi sebagai alat peraba dan perasa untuk mendeteksi makanan berupa deposit lumpur dan detritus. 
Nilai M kepiting bakau di perairan Asahan lebih kecil dibanding nilai F-nya yang mengindikasikan sebagian besar kepiting bakau mati karena penangkapan. Artinya, nilai tingkat pemanfaatan kepiting di Asahan sebesar 0,63 atau lebih besar dari kriteria dari Pauly et al. (1984) yaitu 0,5. Nilai tersebut menunjukkan tingkat pemanfaatan kepiting bakau sudah mencapai $126 \%$, yang berarti sudah berada pada tangkapan yang berlebih (overfishing). Agar sumber kepiting bakau di perairan Asahan dapat terjaga kelestariannya, maka harus dilakukan pengurangan upaya penangkapan sekitar $26 \%$ dari jumlah upaya yang ada saat ini.

\section{KESIMPULAN}

Karakteristik populasi kepiting bakau di perairan Asahan dicirikan dengan pola pertumbuhan bersifat allometrik negatif dan nisbah kelamin kepiting jantan dominan daripada betina dengan lebar karapas ratarata pertama kali tertangkap (CWc) lebih kecil dari ukuran rata-rata pertama kali matang gonad $(\mathrm{CWm})$. Laju kematian akibat penangkapan lebih tinggi daripada kematian alamiah. Tingkat pemanfaatan sumber daya kepiting bakau di perairan Asahan sudah melebihi batas optimal penangkapan/ overfishing sebesar 0,63. Untuk menjamin kelestarian kepiting bakau di perairan Asahan dan sekitarnya, maka perlu dikeluarkan kebijakan pengurangan upaya penangkapan sebesar $26 \%$ dari penangkapan yang saat ini berlangsung.

\section{PERSANTUNAN}

Tulisan ini merupakan kontribusi dari kegiatan Penelitian Karakteristik Biologi Perikanan, Habitat Sumberdaya, dan Potensi Produksi Sumberdaya Ikan di WPP 571 Selat Malaka Tahun Anggaran 2016 pada Balai Penelitian Perikanan Laut, Jakarta. Penulis mengucapkan terima kasih kepada Drs. Suwarso, M.Si sebagai Penanggungjawab kegiatan penelitian WPP 571 Tahun 2016 dan enumerator Nandar Syahrial, S.Pi. Penulis juga mengucapkan terima kasih kepada Prof. Dr. Rosichon Ubaidillah, M. Phill yang telah mereview artikel ini dalam Diklat Teknis Penulisan Imiah (KTI Nasional) Gelombang II Tahun 2018.

\section{DAFTAR PUSTAKA}

Alamsyah, R., \& Megawati. (2017). Hubungan lebar karapas dan berat kepiting bakau yang tertangkap di lingkungan pesisir Sinjai Timur. Disampaikan pada Simposisum Krustasea. KKP-WWF-IPB.
Asmara, H., Riany, E., \& Susanto, A. (2011). Analisa beberapa aspek reproduksi kepiting bakau (Scylla serrata) di perairan Segara Anakan Kabupaten Cilacap Jawa Tengah. Jurnal Metmatika, Sains dan Teknologi, 12 (1), 30-36.

Ball, D,V., \& Rao, K. V. (1984). Marine fisheries. New Delhi/ : Tata Mc. Graw-Hill Publishing Company Limited. 5-24 .

Badan Metereologi, Klimatologi dan Geofisika. (2016). Data suhu harian perairan Selat Malaka 2016. BMKG Stasiun Belawan.

Balai Penelitian Perikanan Laut. (2011). Penelitian dan pengusahaan sumber daya udang penaeid dan krustasea lainnya di WPP Selat Makasar, Laut Flores dan Teluk Bone. Laporan Akhir. Balai Penelitian Perikanan Laut, Pusat Penelitian dan Pengembangan Perikanan, Badan Penelitian dan Pengembangan Kelautan dan Perikanan.

Cholik, F. (1999). Review of mud crab culture research in Indonesia. Proceeding of Mud Crab Aquaculture and Biology. Australian Centre for International Agricultural Research, (ACIAR), Canberra, (78),1420.

Cholik, F. (2005). Review of mud crab culture research in Indonesia, Central Research Institute for Fisheries, PO Box 6650 Slipi, Jakarta, Indonesia, 310CRA.

Cristensen, S, M., Macintosh, D. J., \& Phuong, N., T. (2004). Pond production of the giant mud crabs Scylla paramamosain (Estampador) and $S$. olivacea (Herbst) in the Mekong Delta, Vietnam, using two different supplementary diets. Aqua. Res., 35, 1013-1024.

Edrus, I, N., \& Syam, A.R. (2004). Analisis hasil tangkapan rakang dan bubu pada percobaan penangkapan kepiting di perairan mangrove Maluku. J.Lit. Perikan. Ind. 10 (4), 77 - 86. DOI: http://dx.doi.org/10.15578/jppi.10.4.2004.7786.

Effendie, M, I. (2002). Biologi Perikanan (p. 136) Yogyakarta: Yayasan Pustaka Nusatama.

Fauzi, M., Prasetyo, A. P., Hargiyatno, T. I., Satria, F., \& Utama, A. A. (2013). Hubungan panjang-berat dan faktor kondisi lobster batu (Panulirus penicillatus) di perairan Selatan Gunung Kidul dan 
Pacitan. Bawal, 5 (2), 97-102. DOI: http:// dx.doi.org/10.15578/bawal.5.2.2013.97-102.

Gayanilo, F. C. Jr, Sparre, P., \& Pauly, D. (1993). The FISAT user's guide. FAO Computerized Information Series Fisheries. ICLARM - DIFMAR.

Gunarto., Daud, R., \& Usman. (1999). Kecenderungan penurunan populasi kepiting bakau di perairan muara Sungai Cenrara, Sulawesi Selatan ditinjau dari analisis parameter sumberdaya. Jurnal Penelitian Perikanan Pantai. 5(3), 30 - 37.

Hill, B. J. (1975). Abundance, breeding and growth of the crab Scylla serrata in two South African estuaries. Marine Biology. 32, 119-126.

Karim, M, Y. (2008). Pengaruh salinitas terhadap metabolisme kepiting bakau (Scylla olivacea). Jurnal Perikanan (J. Fish. Sci). X (1), 37-44. https:/ /doi.org/10.22146/jfs.8926.

Kathirvel, M., Kulasekhar, S., \& Balasubramanium, C. P. (2004). Mud crab culture in India. Central Institute of Brackish water Aquaculture (ICAR), 17,60 .

Keenan, C.P., Davie, P.J.F., \& Mann, D.L. (1998). A revision of the genus Scylla De HAAN, 1983 (Crustacea: Decapoda: Brachyura: Portunidae). The Raffles Bulletin of Zoology, 46 (1), 217-245.

King, M. (1995). Fisheries biology, assessment and management (p. 341). Fishing News Book. United Kingdom.

La Sara. (2010). Study on the size structure and population parameters of mud crab Scylla serrata in Lawele Bay, Southeast Sulawesi, Indonesia. Journal of Coastal Development, 13(2), 133-147.

Le Vay, L. (1998). Ecology and stock assessment of Scylla spp. In: Proceedings of the International Forum on the Culture of Portunid Crabs, Boracay, Philippines, December 1-4, 1998.

Marichamy, R., \& Rajapackian, S. (2001). The aquaculture of Scylla species in India. Asian Fish. Sci., $14,231-238$.

Mohanty, S. K., Mohapatra, A., Mohanty, R. K., Bhatta, R. K., \& Pattnaik, A. K. (2006). Occurrence and biological outlines of two species of Scylla (De Haan) in Chilika lagoon, India. Ind. J. Fish., 53, 191-202.
Monoarfa, S., Syamsuddin., \& Hamzah, S.N. (2013). Analisis parameter dinamika populasi kepiting bakau (Scylla serrata) di Kecamatan Kwandang, Kabupaten Gorontalo Utara. Jurnal IImiah Perikanan dan Kelautan. Universitas Negeri Gorontalo, 1(1) 2013, 31-36.

Onrizal. (2010). Perubahan Tutupan Hutan Mangrove di Pantai Timur Sumatera Utara Periode 19772006. Jurnal Biologi Indonesia, 6(2), 163-172. Diakses melalui https://media.neliti.com/media/ publications/76865-ID-perubahan-tutupan-hutanmangrove-di-pant.pdf tanggal 5 Maret 2017 pukul 09.29 Wib.

Pauly, D. (1980). A Selection of a simpel methods for the assessment of the tropical fish stock. FAO Fish. Circ. FIRM/ C 729. Roma. 54 pp.

Pauly, D., Ingles, J., \& Neal, R. (1984). Application to shrimp stocks of objective methods for the estimation of growth, mortality and recruitment related parameters from length frequency data (ELEFAN I and II). In : Penaeid shrimp - their biology and management. Fishing News Book Limited. Farnham-Surrey-England, 220-234.

Pusat Karantina dan Keamanan Hayati lkan. (2016). Pedoman Pemeriksaan/Idetifikasi Jenis Ikan Dilarang Terbatas (Kepiting Bakau/ Scylla spp.). Badan Karantina Ikan, Pengendalian Mutu dan Keamanan Hasil Perikanan. Kementerian Kelautan dan Perikanan.

Realino, B., Teja, A, W., Zahrudin., \& Napitu, A, M. (2006). Pola Spasial dan Temporal Kesuburan Peariran Permukaan Laut Indonesia. Balai Riset dan Observasi Kelautan dan Perikanan, Departemen Kelautan dan Perikanan. Diakses melalui http://www.bpol.litbang.kkp.go.id/old/pdf/ 108867SUDAH $\% 20 \% 20$ Paper\%20Pola $\% 20$ Kesuburan\%20 Perairan\% 20Lin.pdf , tanggal 26 Januari 2018 pukul 11 : 14 Wib.

Ruscoe, I. M., Shelley, C. C., \& Williams, G. R. (2004). The combined effects of temperature and salinity on growth and survival of juvenile giant mud crabs (Scylla serrata Forskal). Aquaculture, 238, 239-247.

Saputra, S. W., Soedarsono,P., \& Sulistyawati,G.A. (2009). Beberapa Aspek Biologi Ikan Kuniran (Upeneus spp.) di Perairan Demak. Jurnal Saintek Perikanan. 5(1), 1-6. 
Siahanenia, L. (2009). Struktur morfologis kepiting bakau (Scylla paramamosain). Jurnal Triton, 5(1), $11-21$.

Simanjuntak, M. (2009). Hubungan faktor lingkungan kimia, fisika terhadap distribusipPlankton di perairan Belitung Timur, Bangka Belitung. Jurnal Perikanan (Journal of Fisheries Sciences). XI (1), 31-45. DOI: https://doi.org/10.22146/jfs.2970.

Sparre, P., \& Venema, S. (1999). Introduksi Pengkajian Stok Ikan Tropis, alih bahasa : Pusat Penelitian dan Pengembangan Perikanan). Buku 1 : Manual (Terjemahan). Badan Penelitian dan Pengembangan Perikanan. Jakarta. 438 p.

Suman, A. (2004). Pola pemanfaatan sumber daya udang dogol (Metapenaeus ensis de Haan) di perairan Cilacap dan sekitarnya. Disertasi. Sekolah Pasca Sarjana, IPB, Bogor.

Syam, A. R.,Suwarso., \& Purnamaningtyas, S.E. (2011). Laju ekploitasi kepiting bakau (Scylla serrata) di Perairan Mangrove Mayangan Subang - Jawa Barat. J. Lit. Perikan. Ind. 17 (3), 201 207. DOI: http://dx.doi.org/10.15578/ jppi.17.3.2011.201-207.

Syech, R., \& Malik, U. (2013). Menentukan nilai reflektan dan salinitas di Perairan Selat Malaka Menggunakan Data Liputan Citra Satelit FY-1D. Prosiding Semirata FMIPA Universitas Lampung, 319-321.
Syech, R ., Junaidi., \& Martin, M. (2007). Estimasi distribusi klorofil-a di Perairan Selat Malaka Menggunakan Data Liputan Citra Satelit FY1D.Diakses http://download.portalgaruda.org/ article. .php?article $=105848 \&$ val $=5122$ pada tanggal 26 Januari 2018 pukul 10:55 Wib.

Wiadnyana, N.N. (2000). Kemelimpahan plankton di perairan Selat Sele, Sorong, Irian Jay a. Majalah IImu Kelautan. 17 (V), 19-28.

Widodo, J., \& Suadi. (2006). Pengelolaan sumberdaya perikanan laut. Yogyakarta: Universitas Gadjah Mada Press.

Wijaya N.I., Yulianda F., Boer M., \& Juwana S. (2010). Biologi populasi kepiting bakau (Scylla serrata F.) di Habitat mMagrove Taman Nasional Kutai Kabupaten Kutai Timur. Jurnal Oseanografi dan Limnologi di Indonesia, (3), 443-461.

Tahmid, M., Fahrudin, A., \& Wardiatno, Y. (2015). Kualitas habitat kepiting Bakau (Scylla serrata) pada ekosisistem mangrove Teluk Bintan, Kabupaten Bintan, Kepulauan Riau. Jurnal IImu dan Teknologi Kelautan Tropis, 7 (2), 535-551.

Yusrudin (2016). Analisis beberapa aspek biologi kepiting bakau (Scylla serrata) di perairan Sukolilo, pantai timur Surabaya. Prosiding Seminar Nasional Kelautan 2016. Universitas Trunojoyo Madura. 